\title{
Carla Fratta, Francesca Torchi, La littérature caribéenne francophone en Italie
}

\section{Antonia Lafratta}

\section{(2) OpenEdition}

\section{Journals}

\section{Edizione digitale}

URL: http://journals.openedition.org/studifrancesi/9359

DOI: 10.4000/studifrancesi.9359

ISSN: 2421-5856

\section{Editore}

Rosenberg \& Sellier

\section{Edizione cartacea}

Data di pubblicazione: 1 juin 2008

Paginazione: 232

ISSN: 0039-2944

\section{Notizia bibliografica digitale}

Antonia Lafratta, «Carla Fratta, Francesca Torchi, La littérature caribéenne francophone en Italie», Studi Francesi [Online], 154 (LII | I) | 2008, online dal 30 novembre 2015, consultato il 12 janvier 2021. URL: http://journals.openedition.org/studifrancesi/9359; DOI: https://doi.org/10.4000/studifrancesi.9359

Questo documento è stato generato automaticamente il 12 janvier 2021.

\section{(c) $(7)$}

Studi Francesi è distribuita con Licenza Creative Commons Attribuzione - Non commerciale - Non opere derivate 4.0 Internazionale. 


\title{
Carla Fratta, Francesca Torchi, La littérature caribéenne francophone en Italie
}

\author{
Antonia Lafratta
}

\section{NOTIZIA}

CARLA FRATTA, FRANCESCA TORCHI, La littérature caribéenne francophone en Italie, in Caribbean Interfaces, Lieven D'HULST, Jean-Marc MOURA, Liesbeth DE BLEEKER \& Nadia LIE eds, Amsterdam-New York, Rodopi, 2007 («Textxet. Studies in Comparative Literature», n. 52), pp. 368.

1 Il volume Caribbean Interfaces affronta, nel suo insieme, la delicata questione dell'identità caraibica. La nozione di interface che compare nel titolo è presa a prestito dal linguaggio informatico per la sua immediata capacità di evocare l'immagine di frontiera, di spazio condiviso che da sempre caratterizza l'arcipelago. Tutti i lavori qui raccolti in inglese e in francese, firmati da ricercatori e studiosi delle maggiori università europee ed americane, si fondano sulla comparison, parola-chiave di un approccio che chiama in causa i concetti di interdisciplinarity, multidisciplinarity e transdisciplinarity (utilizziamo la terminologia anglosassone per non alterare la specificità di ciascun termine). L'articolo di Fratta e Torchi, La littérature caribéenne francophone en Italie, è contenuto nella sezione «Caribbean Research Projects», che raccoglie progetti di ricerca e studi che prendono spunto da un'idea cara a Glissant, e ampiamente condivisa, dei Caraibi come laboratorio insulare della cultura e della letteratura di domani. L'obiettivo di questo lavoro a quattro mani è far conoscere ad un pubblico che non sia solo quello degli specialisti e degli universitari, il tipo di ricerca finora condotto, e che si sta tuttora portando avanti in Italia, sulla letteratura caraibica francofona. Le due voci che intervengono nell'articolo, ognuna con il suo specifico 
contributo, tentano di stabilire «un état des lieux de la littérature caribéenne francophone en territoire italien» (p. 323).

2 Carla Fratta traccia un «Panorama des recherches universitaires», attraverso un excursus storico che cataloga in ordine cronologico gli studi universitari sulla letteratura caraibica realizzati nel nostro paese. Prendendo come punto di partenza gli anni '70 del secolo scorso, che vedono l'autonomia istituzionale degli studi francofoni, la studiosa redige un inventario delle ricerche, non senza aver premesso che un lavoro artisanal come il suo presenta inevitabilmente lacune e limiti e che non mira, pertanto, all'esaustività. Il suo percorso critico si sofferma sul tipo di evoluzione che il discorso letterario sull'area caraibica francofona ha subito attraverso i decenni e documenta l'ingresso nel campo della ricerca anche delle nuove prospettive interdisciplinari e comparatistiche che investono il discorso caraibico. Si conclude infine con un accenno alle tante realtà che cooperano per la diffusione delle letterature francofone caraibiche, come i Gruppi e i Centri di Ricerca che, a partire dagli anni '80 del secolo scorso, contribuiscono col loro prezioso lavoro, insieme all'altrettanto preziosa opera svolta dai convegni e dalle riviste scientifiche (senza contare le tesi di dottorato), a mantenere vivi in Italia l'interesse e il dibattito attorno a questa letteratura.

Complementare del primo, il lavoro di Francesca Torchi approfondisce il discorso sulla diffusione e sulla ricezione della letteratura caraibica francofona in Italia fuori dall'ambito universitario. Partendo da un suo precedente studio che inventariava le opere caraibiche francofone tradotte in italiano, La letteratura francofona dei Caraibi in Italia (in «Francofonia» 46, pp. 49-66, primavera 2004, numero interamente dedicato alla ricezione delle letterature francofone in Italia), Francesca Torchi si propone di indagare le modalità di diffusione e di ricezione di questa letteratura in Italia, attraverso l'analisi delle più recenti pubblicazioni e manifestazioni culturali. L'articolo delle due studiose, che traccia un bilancio sintetico ma attendibile ed esaustivo sulla ricezione della letteratura francofona delle Antille in Italia, costituisce un contributo prezioso agli studi sull'arcipelago caraibico. 